\title{
Variations in Coastal Temperatures on the Southern and Central California Coast
}

\author{
E. J. LIST AND R. C. Y. KOH \\ W. M. Keck Laboratory, California Institute of Technology, Pasadena, Califormia 91125
}

\begin{abstract}
The results of a time series analysis of several years of coastal ocean temperature records are presented for discussion. The records have been analyzed by using digital filtering, covariance and spectral analysis. The low-frequency component of the temperature signal shows a strong seasonal component in southern California. There is little seasonal fluctuation between Point Conception and Pacific Grove. A period of midwinter warming is apparent in southern California. Intermediate frequency components show strong correlations in southern California with the presence of distinct and substantial temperature events occurring almost simultaneously over distances of the order of $200 \mathrm{~km}$. High-trequeıcy compunents have a large standard deviation in summer $\left(0.8^{\circ} \mathrm{C}\right)$ and a low standard deviation in winter $\left(0.4^{\circ} \mathrm{C}\right)$; these components are uncorrelated at stations even a few miles apart. Some coastal stations show a strong possible diurnal component; others, including the offshore islands, show no such components. Morro Bay appears to have an extraordinarily large diurnal component of temperature fluctuation. No attempt has been made in this paper to relate these phenomena to other oceanographic or meteorological variables.
\end{abstract}

\section{INTRODUCTION}

The variation in natural coastal ocean temperatures in California has been the subject of a significant number of previous investigations. Most of these studies have been concerned with the determination of either very short period fluctuations or with mean long-term seasonal changes.

The investigations of short-term phenomena, notably by Ufford [1947a, b, c], Ewing [1950], Arthur [1954], Armstrong and La Fond [1966], Cairns [1967], and Winant [1974] seem to indicate a relationship between temperature fluctuations and internal waves. Others, including Reid [1956], Cairns and La Fond [1966], and Cairns and Nelson [1970], have related the temperature variations to wind and tidal motions. Recent studies by Apel et al. [1975] seem to indicate that internal waves may be tidally generated, as proposed by Zeilon [1934], and that the rapid temperature changes could be caused by internal surf, as predicted by Defant [1950]. Liepper [1955] argued that variations in bottom topography could be responsible for vertical mixing, since topographic undulations could lead to spatial current variations and therefore turbulent mixing. He argued that such turbulence-induced mixing would occur at the same tidal period each day and lead to identifiable masses of water of different temperature. Stevenson and Gorsline [1956] claim to have measured the movement of such water bodies off San Pedro, California.

Studies of long-term, or seasonal, variations of temperature on the coast were carried out by Tully [1938] and Hubbs [1948]. They attempted to relate seasonal changes to atmospheric temperature. Roden [1959] attempted to derive a heat and salt balance for the California Current region but reported disappointing results. Bakun [1973] has recently performed an analysis in an attempt to formulate an upwelling index for the west coast of the United States, and obviously, upwelling should be a significant factor in coastal temperature fluctuations.

Although the above studies have been concerned with particular aspects of the temperature variation in the coastal ocean, there has been no systematic investigation of the range of temporal or spatial scales of the fluctuations except some

Copyright (C) 1976 by the American Geophysical Union. airborne infrared studies by Squire [1971]. This paper is a report on an attempt to determine these scales.

The results of time series analyses of daily temperature data from 18 stations on the Pacific coast of the United States will be presented. The data were collected by the Institute of Marine Resources of the Scripps Institution of Oceanography (SIO) and have been previously distributed by SIO [Robinson, 1972]. The data analyses described herein have not. The data are from stations (Figure 1) primarily in southern California; six stations are north of Point Conception, California, and two stations are outside of California (Neah Bay, Washington, and Columbia River, Oregon).

The emphasis in this paper is on the presentation of the outcomes of the data analysis, since some of the results are surprising in themselves. Essentially no attempt will be made at this time to relate the phenomena revealed by the data analysis to oceanographic or meteorological variables; this will be the subject of a later paper.

\section{The Data}

The data consist of daily temperature readings taken with identically calibrated bucket thermometers. The temperatures were taken, generally at the end of the local pier or jetty, at approximately $8 \mathrm{~A} . \mathrm{M}$. local time by a local citizen or lifeguard equipped with a bucket thermometer provided by SIO (M. K. Robinson, personal communication, 1975). These daily recordings of temperature were then collected and tabulated by Institute of Marine Resources personnel and published by SIO. The records at some stations are complete; at others, gaps of a period of a day or two and up to as long as a week, appear infrequently. The data analyzed for this publication have a minimal number of such omissions and may probably be considered to be one of the best records of Pacific coastal temperatures in the United States. Robinson [1960] has used some of the same data from an earlier period (1950-1959) to assess climatic coherence in temperature and salinity from Alaska to California.

\section{Data Analysis}

The analysis of the temperature data was primarily directed at determining the level of predictability of the recorded temperatures at each station. The first processing was therefore 


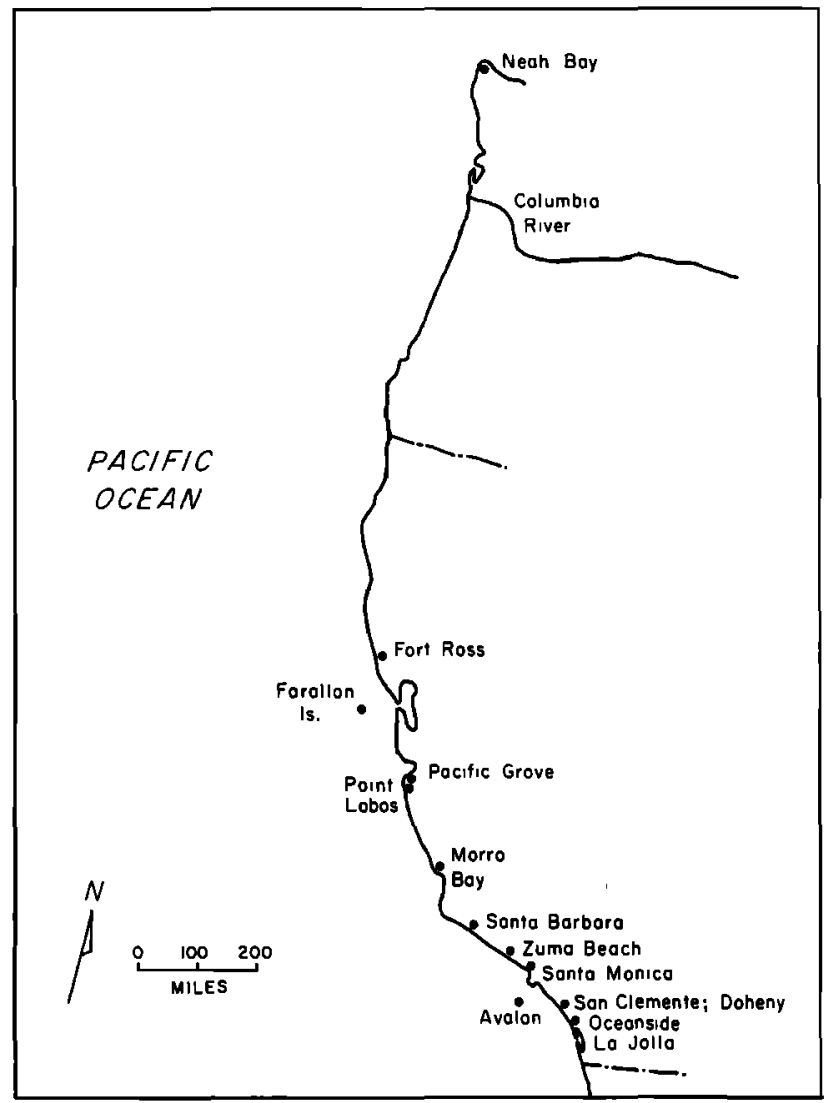

Fig. 1. Temperature measurement stations on the Pacific Coast of the United States $(1 \mathrm{mi}=1.6 \mathrm{~km})$.

simple digital filtering to decompose the temperature signals into three frequency bands. A simple comb filter with halfpower cutoffs at frequencies of 0.059 and $0.0084 \mathrm{~d}^{-1}$ was used. The first frequency corresponds to a half-power cutoff period of $17 \mathrm{~d}$, and the second to a period of $120 \mathrm{~d}$. The temperature signal is thus decomposed into three bands with periods of essentially 2 weeks or less, 2 weeks to 1 season, and 1 season to many years. An example of the results of such processing of the daily temperature records for Oceanside, California, for the period November 1966 to September 1971 is shown in Figure 2. The upper record (the long-period component) shows a well-defined seasonal fluctuation with a warming in summer and cooling in winter. However, in midwinter there appears to be an anomalous warming of the ocean. Records for all southern California stations show this feature, although not every winter. A speculative explanation of the phenomenon has been suggested by Koh and List [1975].

The second trace in Figure 2 is the high-frequency component, or fluctuations with periods of 2 weeks and less. It can be seen that there is an almost universal increase in the variance of this signal in summer and a decrease in winter, as found previously by Cairns and Nelson [1970] for Mission Beach, California. This will be discussed in greater detail subsequently. The third trace is the unfiltered raw data. The fourth trace is the midfrequency component of the temperature signal. It can be seen to comprise about 8 or so distinct temperature events each year, some of quite substantial magnitude.

Similar digital filtering was carried out for 13 stations on the west coast, and the results of these analyses are very informative. In Figure 3 the long-period frequency bands are presented for several stations for the years 1968-1970. It can easily be seen that all the southern California stations (La Jolla to Santa Barbara) are well correlated, showing a well-defined seasonal pattern. There is, however, a lag in the attainment of the midsummer peak temperature associated with a northward displacement of stations. North of Point Conception the seasonal pattern disappears, the result being that Morro Bay and Pacific Grove, although apparently correlated, show little seasonal fluctuation. North of California the seasonal pattern is again established, but the peak temperature sometimes occurs relatively early in the summer.

The high-frequency signals are shown in Figure 4a. The Neah Bay records show a high-intensity fluctuation in summer and a lower intensity in winter, whereas the Columbia River

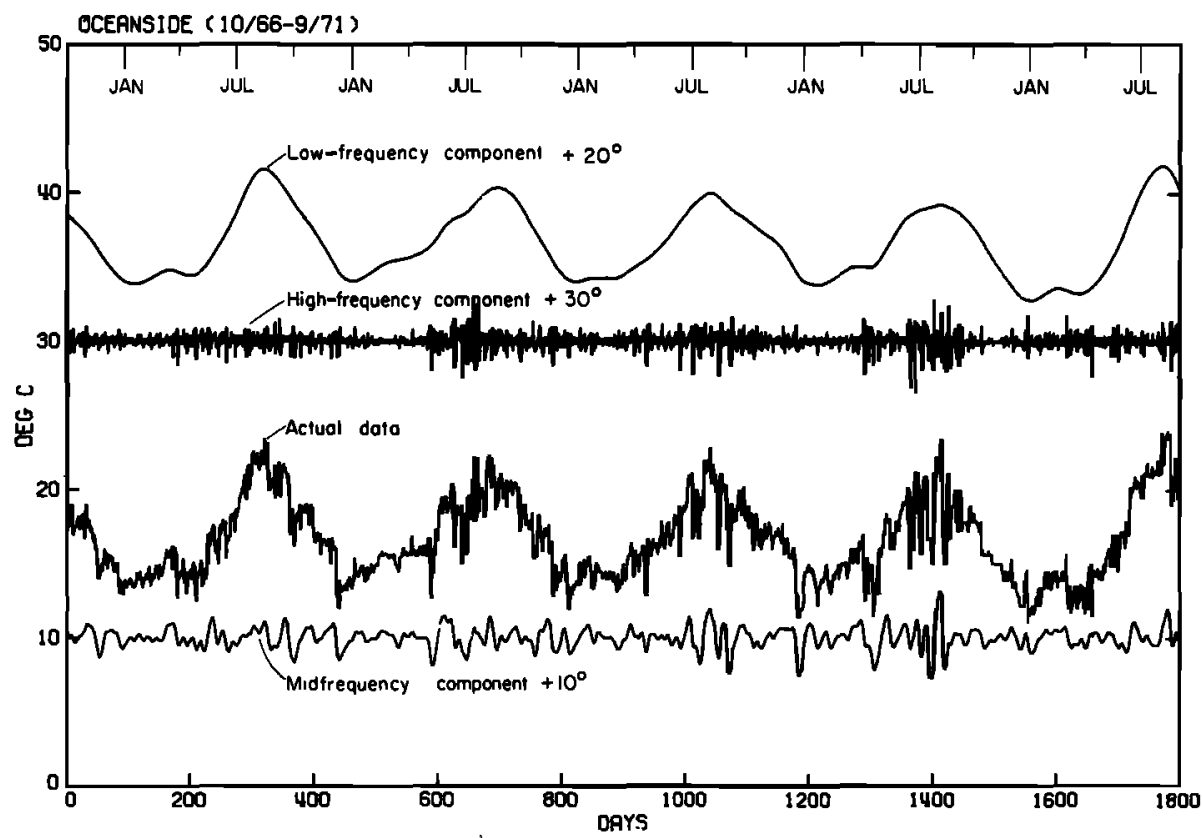

Fig. 2. Typical southern California daily temperature record (Oceanside, California, beginning October 1, 1966) decomposed into frequency bands (see text for frequency definitions). 


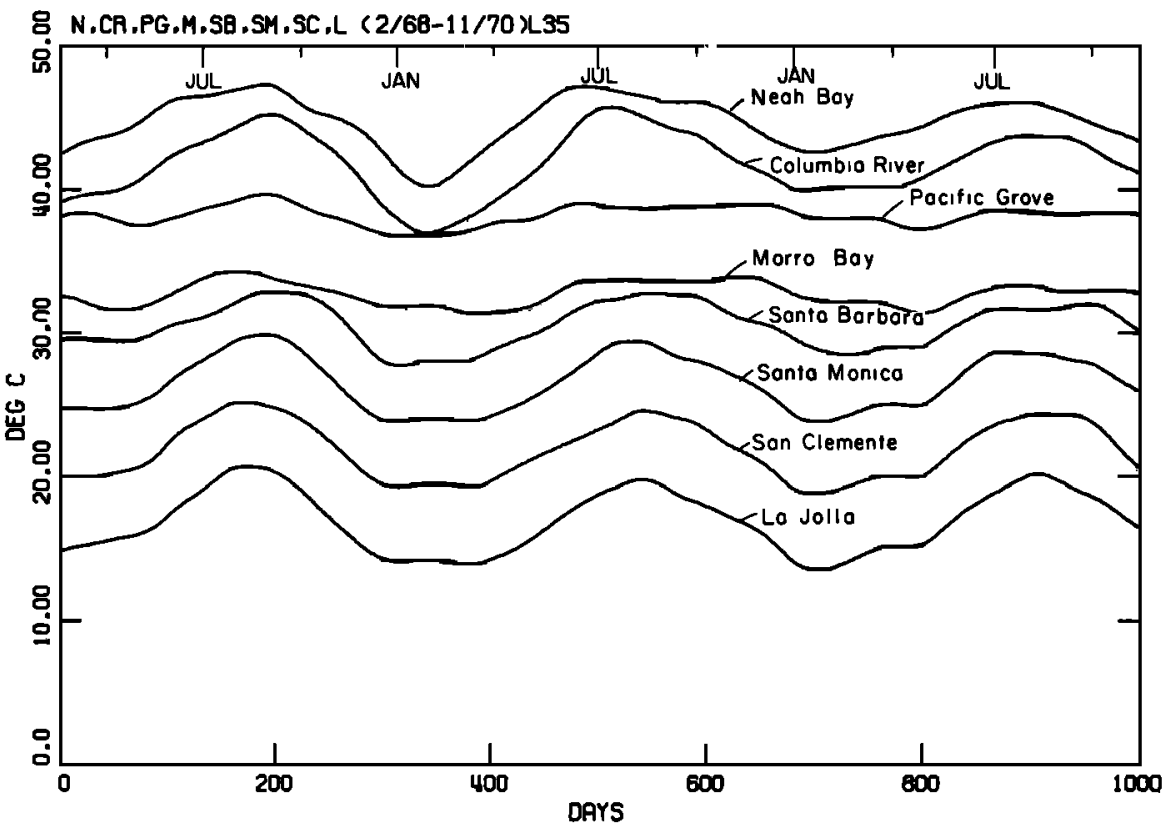

Fig. 3. Low-frequency component of temperature variations at selected Pacific coast stations (beginning February 21, 1968). (Each curve is displaced $+5^{\circ}$ from the curve below it.)

station shows a relatively high intensity except for a brief period in spring each year. At the other extreme, the highfrequency component at Pacific Grove shows only a modest increase in intensity in summer relative to winter. However, Morro Bay, which is also north of Point Conception, but much further south of Monterey Bay than Pacific Grove, shows the well-defined summer high-winter low intensities common to the southern California stations. When the amplitude modulation of these high-frequency fluctuations is plotted (Figure $4 b$ ), it can easily be seen that apart from the seasonal pattern there is essentially no correlation between the various stations at this frequency level; each fluctuation appears to be a purely local phenomenon.

When the intermediate frequency bands at each of the above stations are plotted (Figure 5), it can be seen that there is some correlation between the signals at Neah Bay and Columbia River but that these stations are uncorrelated from the California data. There does appear to be a small correlation of events between Pacific Grove and Morro Bay, but the level of correlation with the southern California stations is minor. However, there are some well-defined events in southern California whose presence is felt, in a minor way, as far north as Morro Bay. In southern California the apparent correlation between stations is high, although there are distinct events in the San Clemente-La Jolla area which have only a small influence on the Santa Monica and Santa Barbara records. On other occasions, events are common to the entire southern California bight stations. It is apparent therefore that the phenomena

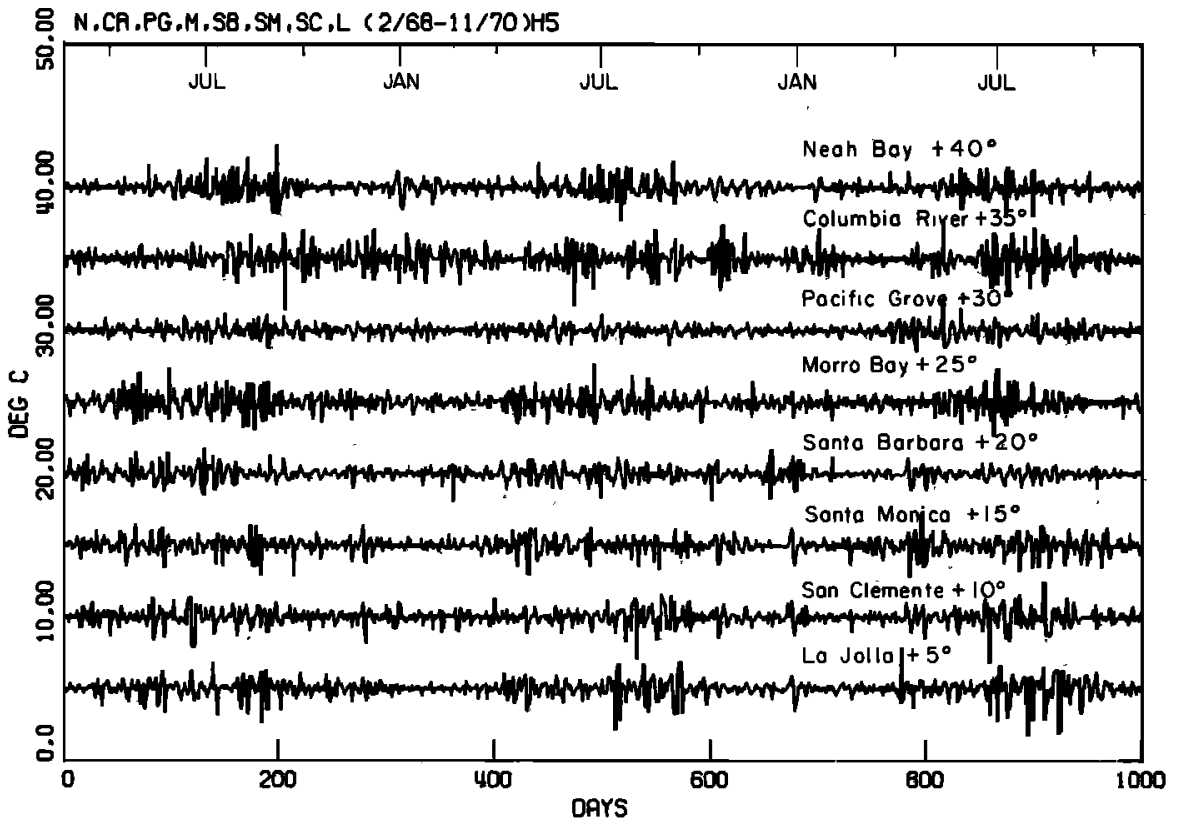

Fig. 4a. High-frequency component of temperature variations at selected Pacific coast stations (beginning February 21, 1968) referred to zero mean. 


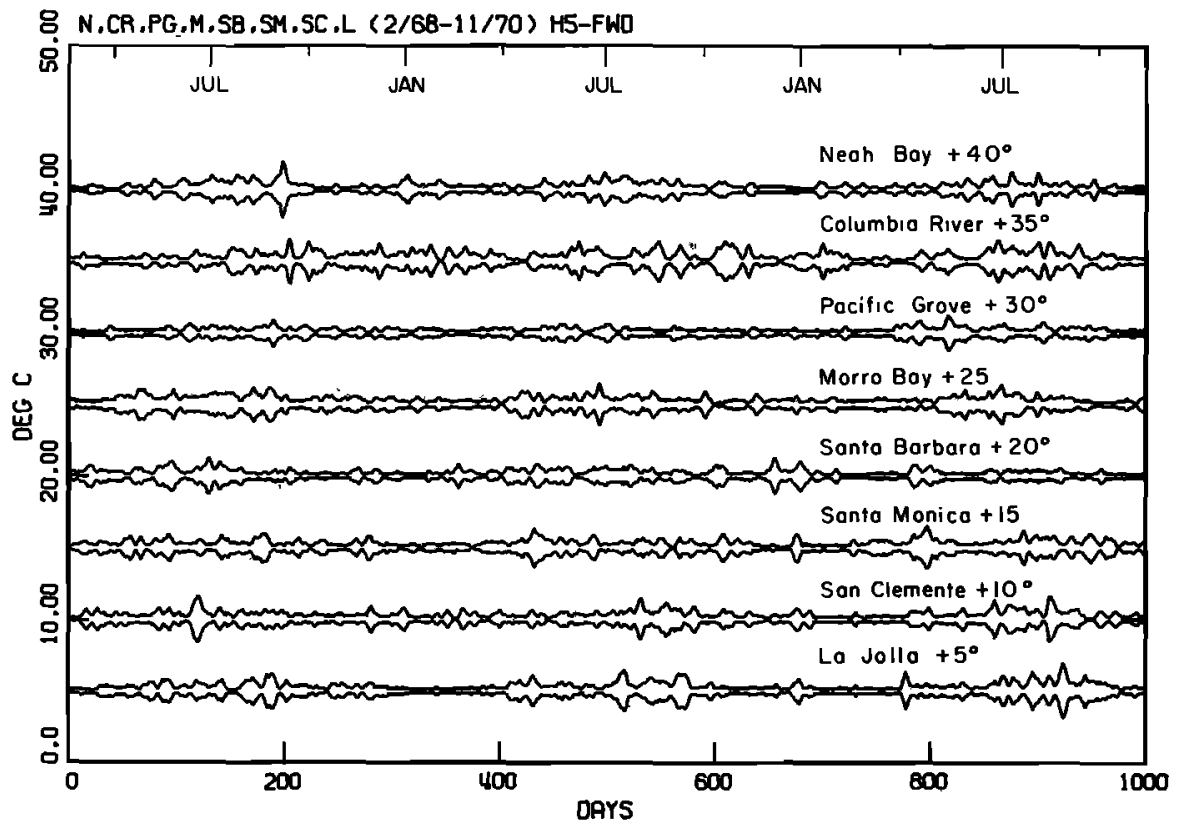

Fig. 4b. Amplitude modulation of high-frequency component of temperature variations at selected Pacific coast stations (beginning February 21, 1968) referred to zero mean.

which give rise to these events extend over areas from as far as La Jolla to Santa Barbara but more often only over distances of the scale of from La Jolla to San Clemente or Santa Monica to Santa Barbara. The explanation of these events is currently under investigation.

\section{CORRELATIONS AND SPECTRA}

The degree of correlation of the records from different temperature measuring stations that is apparent in the results presented above was analyzed in a more systematic fashion by use of covariance and correlation analysis. The data were first high pass filtered with a half-power cutoff at 120 days to remove the seasonal fluctuations. The filtered data were then assumed periodic with a period of 1024 days and the covariances formed for various lags.

The correlation between Neah Bay, Washington, and La Jolla, California, was found to be essentially zero (correlation coefficient 0.03 ), which is hardly surprising. At the other extreme, the correlation between north and south Point Lobos is comparatively high (correlation coefficient of 0.77 ). In northern California there appears to be a marginal correlation between Fort Ross and the three stations at the south side of Monterey Bay (north and south Point Lobos and Pacific Grove): correlation coefficients of $0.46,0.56$, and 0.36 were found, respectively. For the intermediate frequency components alone these correlation coefficients rise to $0.67,0.77$,

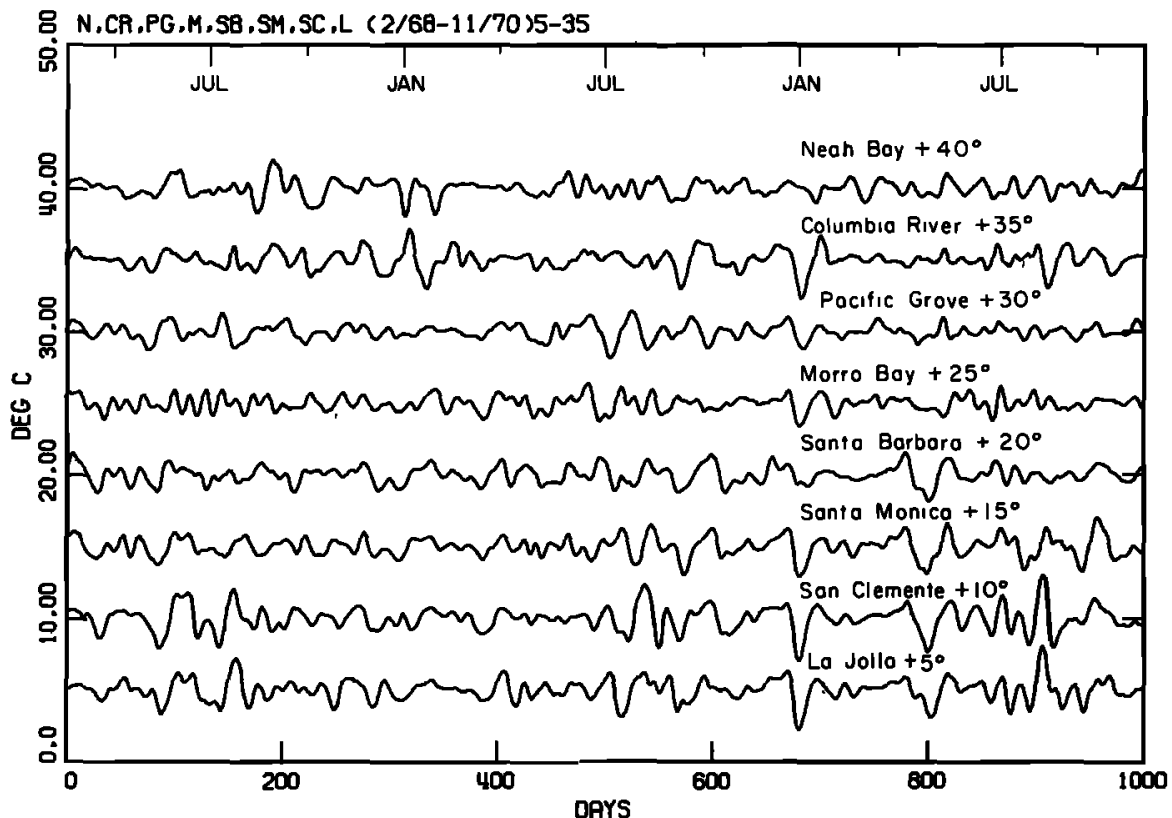

Fig. 5. Intermediate frequency temperature variations at selected Pacific coast stations (beginning February 21, 1968) referred to zero mean. 
and 0.49 , respectively. There is some phase shift apparent in the covariance between stations, although it is probably not significant, as there is no well-defined trend. The Farallon Islands seem to be uncorrelated with the coastal stations. The maximum correlation is with north Point Lobos, and the correlation coefficient is only 0.19 . However, for the intermediate frequency component alone the correlation coefficient relative to Fort Ross does rise to 0.49 in some years.

In southern California all the stations seem to be relatively more highly correlated, including to a lesser degree, Avalon on Santa Catalina Island (Figure 6). There is little if any phase shift in the covariance between stations in southern California, confirming that the correlation is associated with a phenomenon with a large length scale.

The covariances of Morro Bay and other stations are interesting, as they disclose a strong sinusoidal component for some stations located on the coast but not with offshore stations, such as the Farallon Islands or Avalon. In Figure 7 the covariances of Morro Bay with Neah Bay, Fort Ross, Pacific Grove, Santa Barbara, Santa Monica, and to a lesser extent, La Jolla all show this sinusoidal component with a period of about $14.7 \mathrm{~d}$ corresponding to a frequency of 0.068 cycles $/ \mathrm{d}$.

A possible explanation for this oscillatory behavior of the covariances is apparent when the spectra of the temperature records are considered. Figure 8 shows the spectra for Morro Bay, Neah Bay, Pacific Grove, Santa Barbara, Santa Monica, La Jolla, and the offshore islands. There is a spectral peak at a frequency of 0.068 cycles/ $d$ in all of the coastal station spectra (with the notable exception of La Jolla) but not in the spectra for Avalon or the Farallon Islands. The peak in the Morro Bay spectrum is quite exceptional. These spectral peaks could be associated with aliases of the tidal frequencies. Owing to the fact that the Nyquist frequency is 0.5 cycles/d, both the semidiurnal and diurnal tidal frequencies fold into a frequency of approximately 0.068 cycles $/ \mathrm{d}$. It appears to be more than a coincidence that bay temperature spectra show this folding but that offshore island spectra do not. A temperature spectrum from Long Beach harbor (Figure 9), obtained with a folding frequency of 0.5 cycle/hour, shows well-defined semidiurnal and diurnal peaks, and it seems likely that peaks such as these will occur in other bay spectra. The intensity of the peaks for Morro Bay is surprising, however. Cairns and Nelson [1970] found diurnal peaks at middepths at Mission Beach, California. However, it should also be noted that the semidiurnal and diurnal partial high and low waters coincide with a period of $14.3 \mathrm{~d}$, and the strong component with this frequency could be associated with the spring and neap tides.

There is some interest in comparing two neighboring sta-

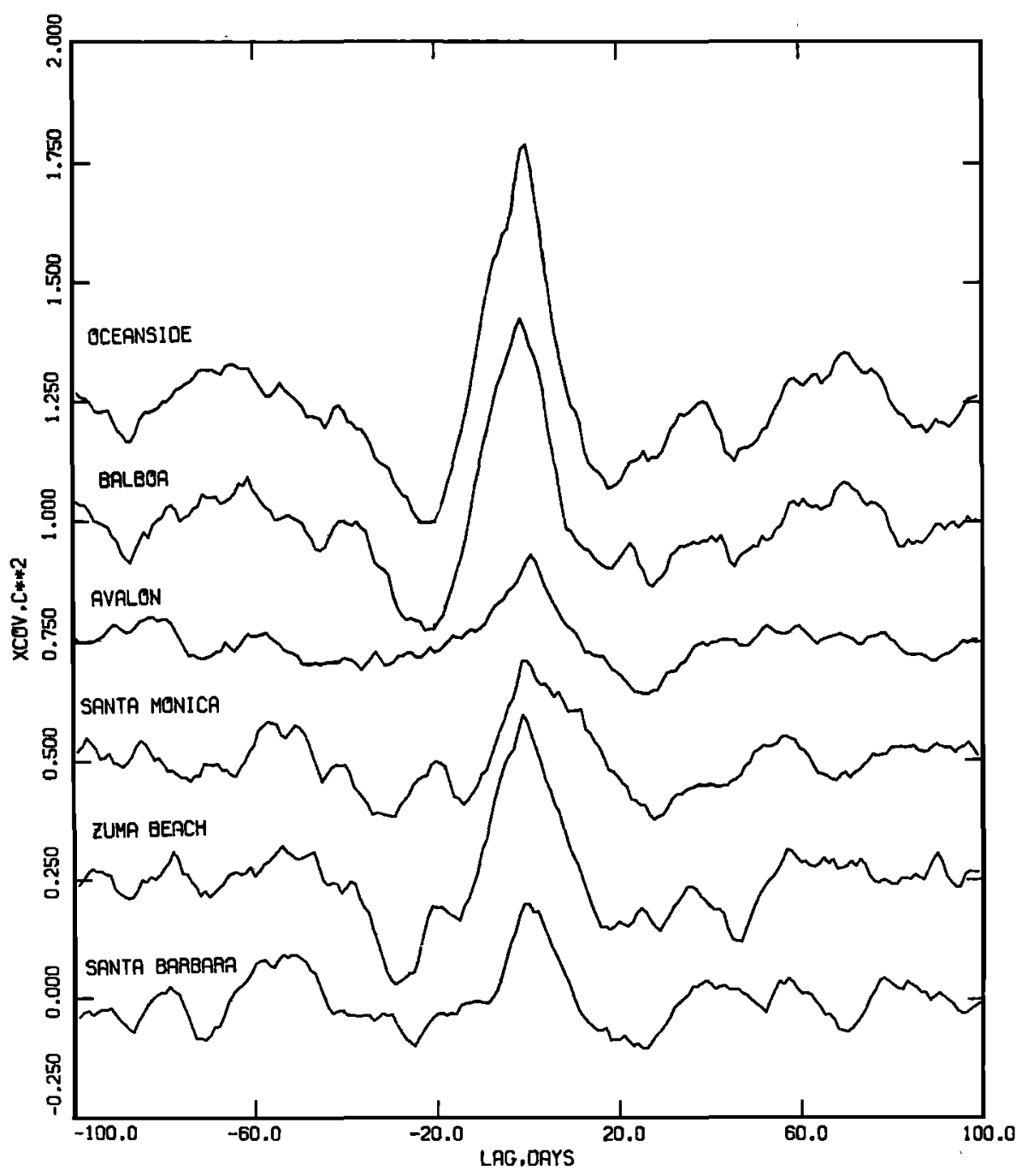

Fig. 6. Covariance of the daily temperature record at La Jolla, California, with selected southern California station temperature records for the period February 21, 1968 through December 11, 1970 (seasonal trends removed and each curve displaced 0.25 from the curve below). 


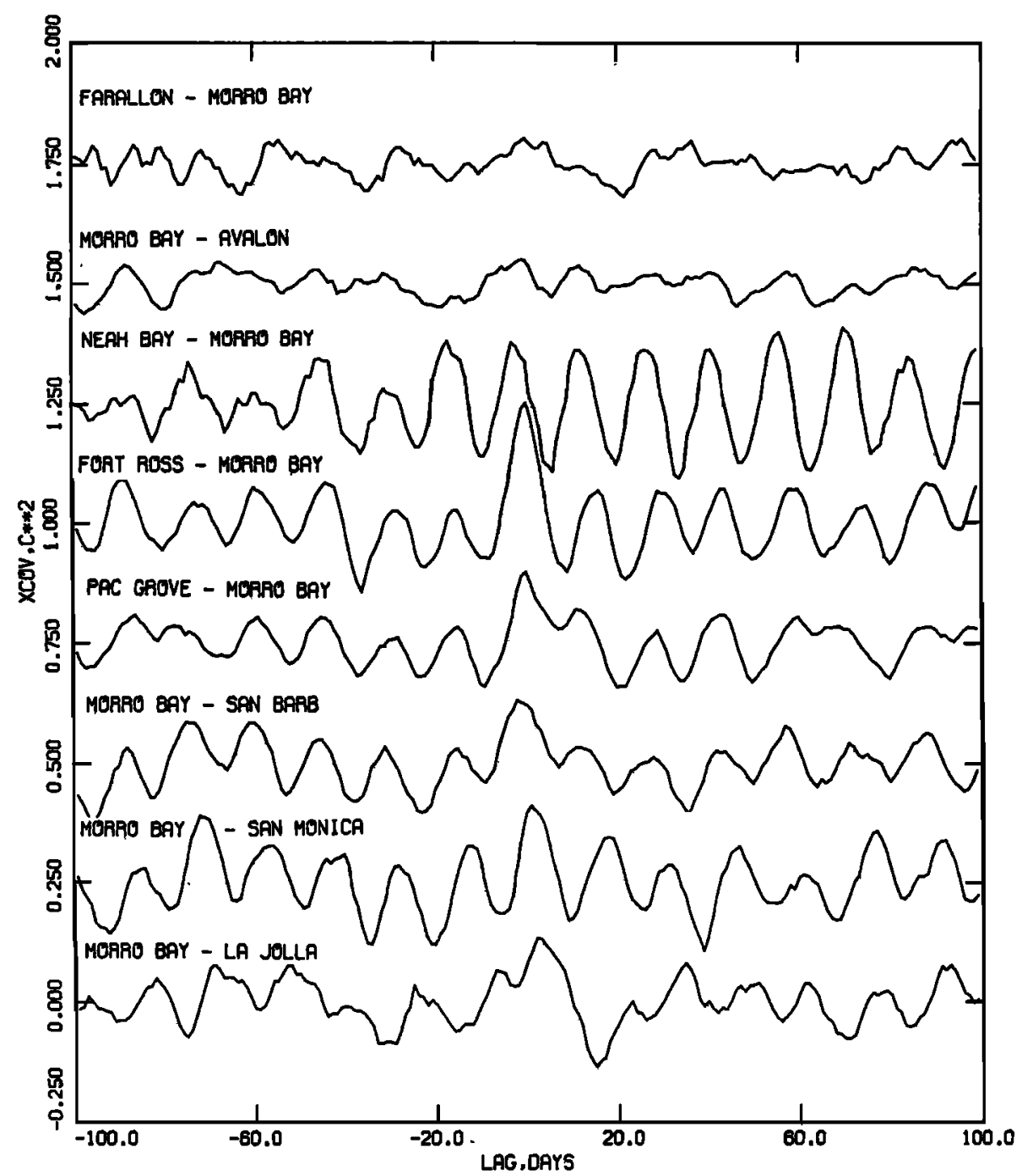

Fig. 7. Covariance of the daily temperature record at Morro Bay, California, with selected Pacific coast station temperature records for the period February 21, 1968, through December 11, 1970. (Seasonal trends removed and each curve displaced 0.25 from the curve below.)

tions in southern California, since the coherence of the temperature records of two adjacent stations provides some insight into the scale of the high-frequency fluctuations. The low, intermediate, and high frequency data for San Clemente and Doheny Beach are shown in Figure 10. Doheny Beach and San Clemente are about $5 \mathrm{~km}$ apart and are about $70 \mathrm{~km}$ north of La Jolla. It is readily seen that there is a very high degree of correlation in the low and intermediate frequency bands, but there is little correlation in the high-frequency measurements. One may reasonably conclude that the high-frequency fluctuations are caused by a phenomenon whose length scale is less than the separation of the two stations. The amplitude of these fluctuations also appears to be somewhat higher at Doheny Beach. Figure 11 shows the surface and bottom $(10 \mathrm{~m})$ temperature records at the La Jolla pier. It can be seen that in the summertime there is a well-defined thermocline apparent in the low-frequency record. The thermocline vanishes in winter as one would expect. The intermediate frequency records show a very high degree of correlation. The high-frequency component shows that the surface and bottom are essentially uncorrelated and that the bottom temperatures have significantly greater variation in summer. This result is to be expected from the recent work of Winant [1974], who has found rapid and substantial temperature changes at the bottom near the Scripps pier, and Cairns [1967], who found internal waves with strong asymmetry in shallow water. These results seem to indicate that the high-frequency variation is associated with a vertical mixing process and the intermediate frequency variation with changes in the water body. The fact that such changes occur over substantial distances and virtually simultaneously suggests a meteorological process. As Bakun [1973] has shown on a relatively large scale, there are significant variations in the geostrophic-induced upwelling along the coast, and this could be responsible, although this is completely speculative at this juncture. A complete analysis of weather and ocean patterns in the southern and central California region will be the subject of a later communication. In the meantime the following conclusions can be drawn.

\section{Summary and Conclusions}

Analysis of 3 years of daily temperature readings for the U.S. coastal Pacific Ocean has disclosed the following results: 


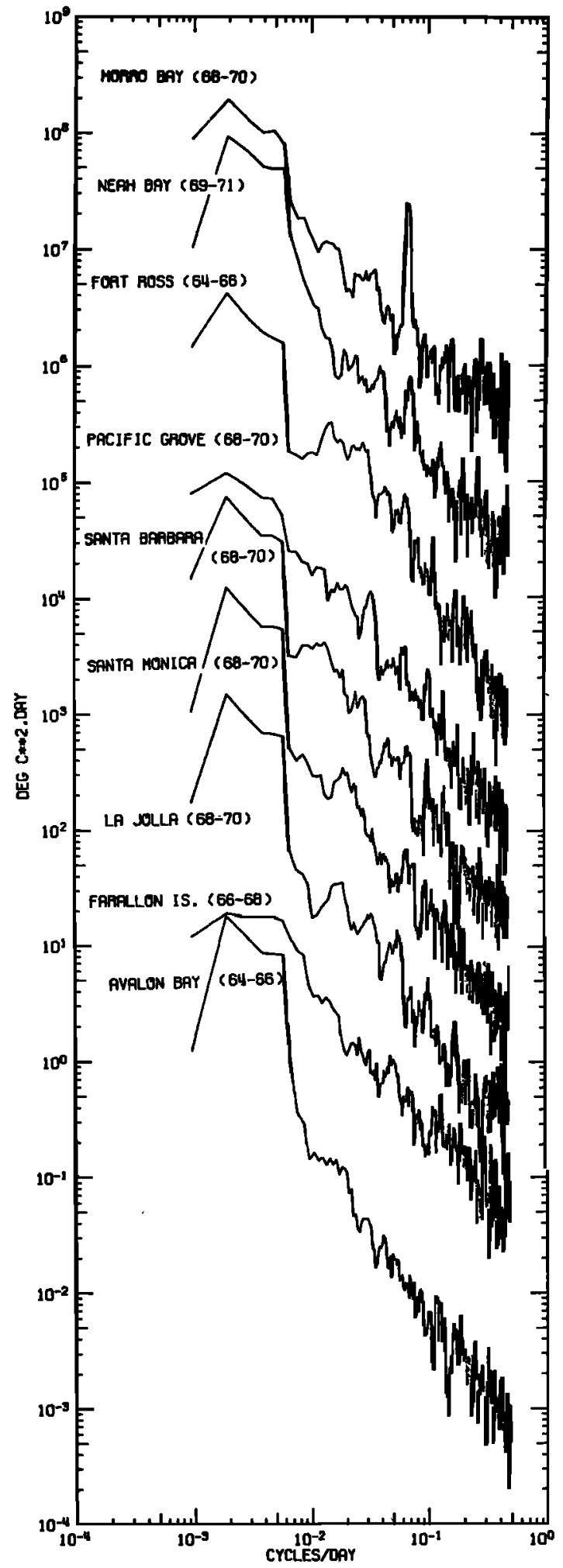

Fig. 8. Temperature record spectra at selected Pacific coast stations (each curve is displaced by $10^{1}$ from the curve below).

1. There is a well-defined seasonal temperature fluctuation in southern California, but it is essentially absent between Point Conception and south of Monterey Bay, California. The

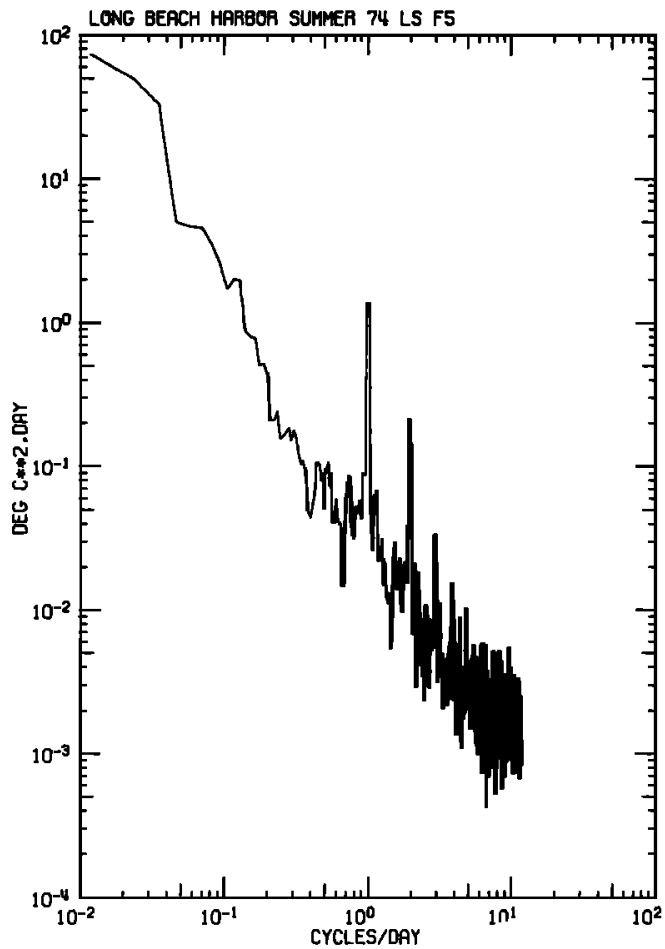

Fig. 9. Temperature record spectrum for Long Beach harbor (summer 1974).

seasonal pattern seemingly reappears in the coastal waters north of California.

2. Apparently random temperature fluctuations with a period of less than 2 weeks are a feature of the summer temperature records in both northern and southern coastal waters. The standard deviation of these fluctuations is minimal in central California but of the order of $0.8^{\circ} \mathrm{C}$ in the summer in southern California and north of California. The intensity of these fluctuations reduces substantially in winter to a standard deviation of about $0.4^{\circ} \mathrm{C}$. The fluctuations show almost no correlation between temperature stations a few miles apart.

3. Intermediate frequency records (period of 2-16 weeks) show a strong correlation in southern waters but are essentially uncorrelated in northern waters. There is no lag in the correlations between stations, implying that the length scale of the phenomenon causing these fluctuations must be greater than $150 \mathrm{~km}$.

4. The temperatures at the offshore islands, Farallon and Santa Catalina, seem to have little tidal component in their fluctuations and have only a minor correlation with coastal waters.

5. Temperature fluctuations at Neah Bay, Morro Bay, Pacific Grove, Santa Barbara, and Santa Monica appear to have a possible strong diurnal component.

6. Although the coherence of the temperature records between stations a few miles apart is high on many occasions, the temperature difference between such stations will at times exceed $2.0^{\circ} \mathrm{C}$ and often exceed $1.0^{\circ} \mathrm{C}$.

7. The high-frequency temperature fluctuations at the bottom (10-m depth) appear to be uncorrelated with surface fluctuations and to exceed them in intensity during the period when there is a well-established mean thermocline.

8. Mean temperatures at stations a few miles apart on the coast may vary by as much as $1^{\circ} \mathrm{C}$. 


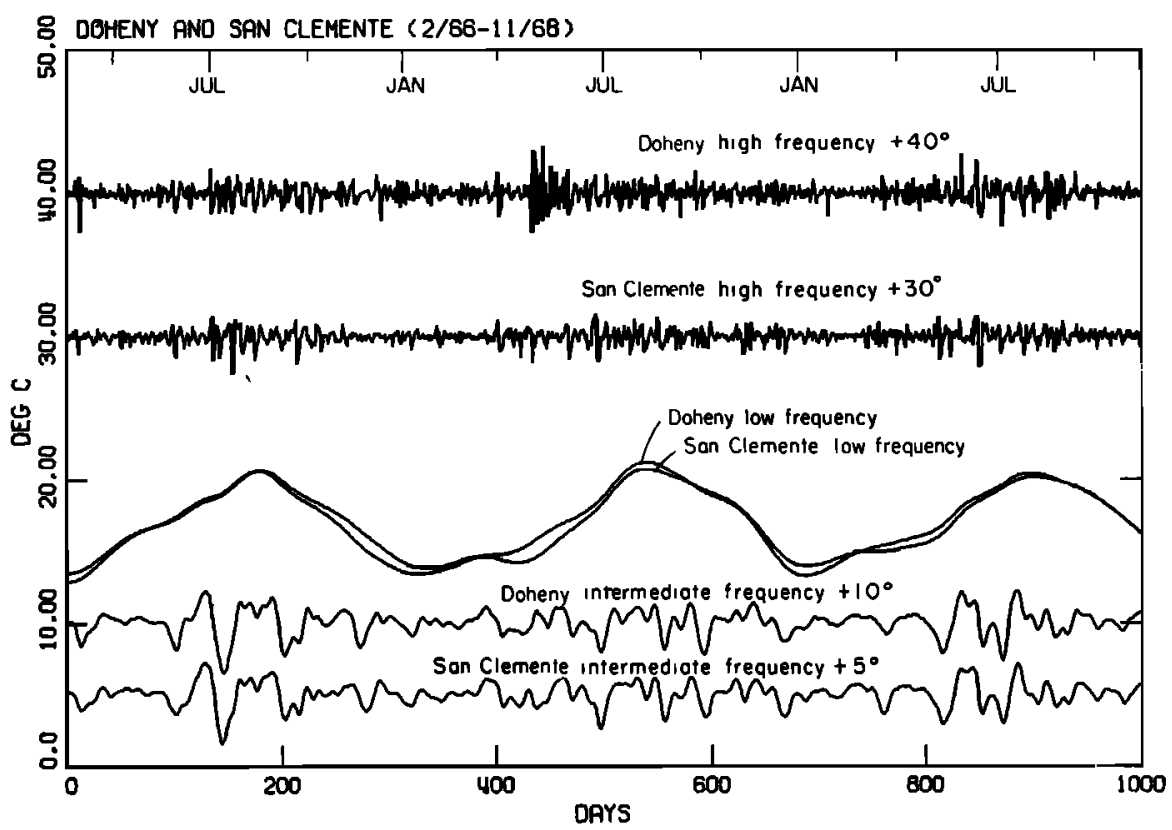

Fig. 10. High, low, and intermediate frequency components of temperature variation at Doheny Beach and San Clemente beginning February 21, 1966.

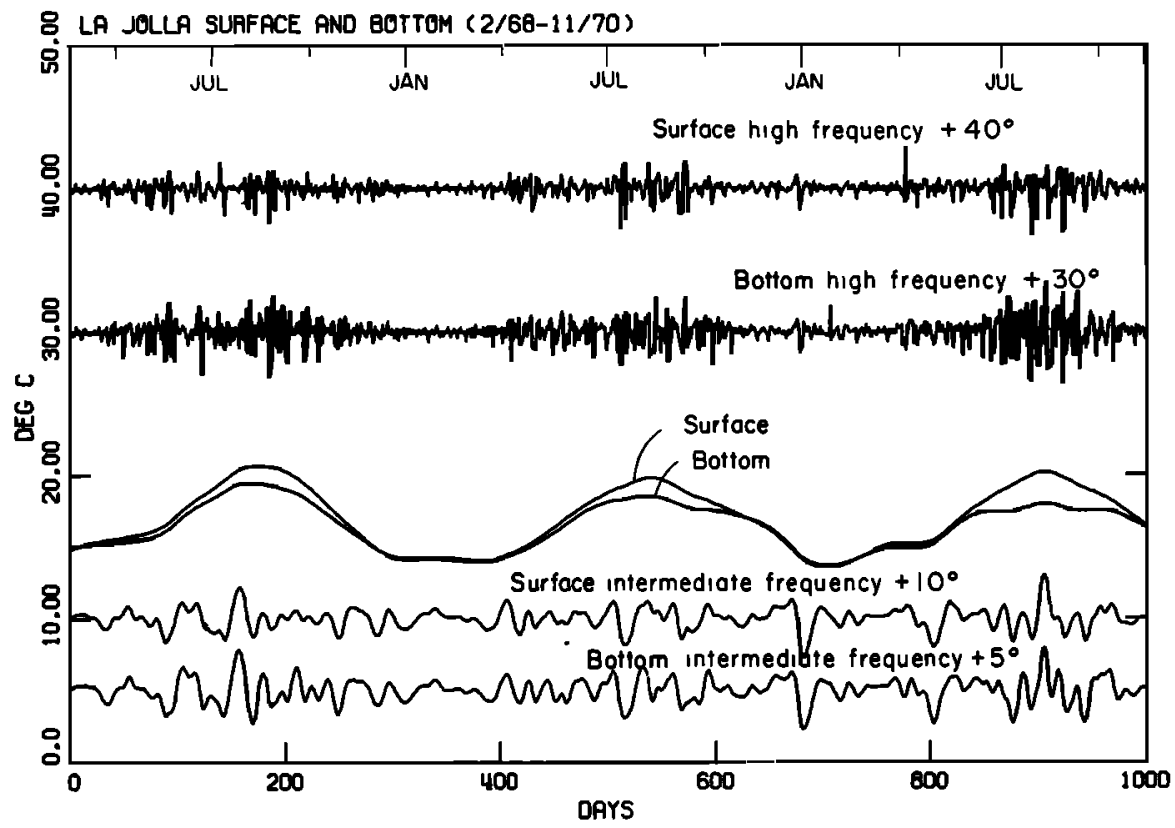

Fig. 11. High, low, and intermediate frequency components of temperature variation at La Jolla, California, at the surface and bottom, beginning February 21, 1968.

Acknowledgments. The authors gratefully acknowledge the assistance of the Ocean Temperature Records Group of the Institute of Marine Resources, Scripps Institution of Oceanography, who kindly made available the temperature data. In particular, Margaret Robinson and Frances Wilkes are to be thanked for their helpful cooperation. This paper was prepared with support from the Ford Motor Company Energy Fund at the California Institute of Technology and from the National Science Foundation under grant ENG75-02985.

\section{REFERENCES}

Apel, J. R., J. R. Proni, H. M. Byrne, and R. L. Sellers, Near simultaneous observations of intermittent internal waves on the continental shelf from ship and spacecraft, Geophys. Res. Lett., 2(4), 128-131, 1975.

Armstrong, F. A. J., and E. C. La Fond, Nutrient concentrations related to internal waves and turbidity, Limnol. Oceanogr., Il, 538-547, 1966.

Arthur, R. S., Oscillations in sea temperature at Scripps and Oceanside piers, Deep Sea Res., 2, 107-121, 1954.

Bakun, A., Coastal upwelling indices, West Coast of North America, 1946-1971, NOAA Tech. Rep. NMFS SSRF-671, 103 pp., Nat. Oceanic and Atmos. Admin., W ashington, D. C., June 1973.

Cairns, J. L., Asymmetry of internal tidal waves in shallow coastal waters, J. Geophys. Res., 72(14), 3563-3565, 1967.

Cairns, J. L., and E. C. La Fond, Periodic motions of the seasonal thermocline along the southern California coast, J. Geophys. Res., $71(16), 3903-3915,1966$.

Cairns, J. L., and K. W. Nelson, A description of the seasonal thermocline cycle in shallow coastal water, J. Geophys. Res., 75(6), 1127-1131, 1970.

Defant, A., On the origin of internal tide waves in the open sea, $J$. Mar. Res., 9, 111-119, 1950. 
Ewing, G., Slicks, surface films and internal waves, J. Mar. Res., 9, 161-187, 1950.

Hubbs, C. L., Changes in the fish fauna of western North America correlated with changes in ocean temperature, J. Mar. Res., 7, 459-482, 1948.

Koh, R. C. Y., and E. J. List, Natural ocean temperatures in southern California and their relation to ocean thermal discharges, paper presented at the 16th IAHR Congress, Int. Ass. Hydraul. Res., São Paulo, Brazil, July 1975.

Liepper, D. F., Sea temperature variations associated with tidal currents in stratified shallow water over an irregular bottom, J. Mar. Res., 14, 234-252, 1955.

Reid, J. L., Jr., Observations of internal tides in October, 1950, Eos Trans. $A G U, 37(3), 278-286,1956$.

Robinson, M. K., The use of a common reference period for evaluating climatic.coherence in temperature and salinity records from Alaska to California 1959-1960, Invest. Rep. 8, pp. 121-130, Calif. Coop. Oceanic Fish., Mar. Res. Comm., 1960.

Robinson, M. K., Surface water temperatures at shore stations, U.S. west coast and Baja California, 1964-1972, Scripps Inst. of Oceanogr., La Jolla, Calif., 1972.

Roden, G. I., On the heat and salt balance of the California current region, J. Mar. Res., 67(6), 2491-2497, 1959.
Squire, J. L., Measurements of the sea surface temperature on the eastern Pacific continental shelf using airborne infrared radiometry, Oceanogr. Rep. 47, CG 373-47, U.S. Coast Guard, Washington, D. C., 1971.

Stevenson, R. E., and D. S. Gorsline, A shoreward movement of cool subsurface water, Eos Trans. AGU, 37(5), 553-557, 1956.

Tully, J. P., Some relations between meteorology and coast gradient currents off the Pacific coast of North America, Eos Trans. AGU, 176-183, 1938.

Ufford, C. W., Internal waves in the ocean, Eos Trans. AGU, 28(1), 79-86, $1947 a$.

Ufford, C. W., Internal waves measured at three stations, Eos Trans. $A G U, 28(1), 87-95,1947 b$.

Ufford, C. W., The theory of internal waves, Eos Trans. $A G U, 28(1)$, 96-101, 1947c.

Winant, C., Internal surges in coastal waters, J. Geophys. Res., 79(30), 4523-4526, 1974.

Zeilon, M., Experiments on boundary tides, Goeteborgs Kugl. Vetensk. Samhaelles Handl., Ser. B, 3(10), 8 pp., 1934.

(Received June 30, 1975; revised December 15, 1975; accepted December 19, 1975.) 